\title{
Article \\ OsBIC1 Directly Interacts with OsCRYs to Regulate Leaf Sheath Length through Mediating GA-Responsive Pathway
}

\author{
Cong Li ${ }^{1,2,+}$, Xin Wang ${ }^{1,+}{ }^{,}$Liya Zhang ${ }^{1,+}$, Chunyu Zhang ${ }^{1}$, Chunsheng $\mathrm{Yu}^{1}{ }^{1}$, Tao Zhao ${ }^{1} \mathbb{1}$, Bin Liu ${ }^{1}$, \\ Hongyu $\mathrm{Li}^{1, *}$ (1) and Jun Liu ${ }^{1, *}$ \\ 1 Institute of Crop Sciences, Chinese Academy of Agricultural Sciences, Beijing 100081, China; \\ licong202103@163.com (C.L.); WX940709@163.com (X.W.); zly13070156288@163.com (L.Z.); \\ n_zcy@163.com (C.Z.); yuchunsheng1989@163.com (C.Y.); zhaotao02@caas.cn (T.Z.); liubin05@caas.cn (B.L.) \\ 2 Institute of Nanfan \& Seed Industry, Guangdong Academy of Sciences, Guangzhou 510316, China \\ * Correspondence: lihongyu@caas.cn (H.L.); liujun02@caas.cn (J.L.) \\ + These authors contributed equally to this work.
}

Citation: Li, C.; Wang, X.; Zhang, L.; Zhang, C.; Yu, C.; Zhao, T.; Liu, B.; Li, H.; Liu, J. OsBIC1 Directly Interacts with OsCRYs to Regulate Leaf Sheath Length through Mediating GA-Responsive Pathway. Int. J. Mol. Sci. 2022, 23, 287. https:// doi.org/10.3390/ijms23010287

Academic Editor: Lars Matthias Voll

Received: 31 October 2021

Accepted: 23 December 2021

Published: 28 December 2021

Publisher's Note: MDPI stays neutral with regard to jurisdictional claims in published maps and institutional affiliations.

Copyright: (C) 2021 by the authors. Licensee MDPI, Basel, Switzerland. This article is an open access article distributed under the terms and conditions of the Creative Commons Attribution (CC BY) license (https:// creativecommons.org/licenses/by/ $4.0 /)$.

\begin{abstract}
Cryptochrome 1 and 2 (CRY1 and CRY2) are blue light receptors involved in the regulation of hypocotyl elongation, cotyledon expansion, and flowering time in Arabidopsis thaliana. Two cryptochrome-interacting proteins, Blue-light Inhibitor of Cryptochrome 1 and 2 (BIC1 and BIC2), have been found in Arabidopsis. BIC1 plays critical roles in suppressing the physiological activities of CRY2, which include the blue light-dependent dimerization, phosphorylation, photobody formation, and degradation process, but the functional characterization of BIC protein in other crops has not yet been performed. To investigate the function of BIC protein in rice (Oryza sativa), two homologous genes of Arabidopsis BIC1 and BIC2, namely OsBIC1 and OsBIC2 (OsBICs), were identified. The overexpression of OsBIC1 and OsBIC2 led to increased leaf sheath length, whereas mutations in OsBIC1 displayed shorter leaf sheath in a blue light intensity-dependent manner. OsBIC1 regulated blue light-induced leaf sheath elongation through direct interaction with OsCRY1a, OsCRY1b, and OsCRY2 (OsCRYs). Longitudinal sections of the second leaf sheath demonstrated that OsBIC1 and OsCRYs controlled leaf sheath length by influencing the ratio of epidermal cells with different lengths. RNA-sequencing (RNA-seq) and quantitative Real-Time Polymerase Chain Reaction (qRT-PCR) analysis further proved that OsBIC1 and OsCRYs regulated similar transcriptome changes in regulating Gibberellic Acids (GA)-responsive pathway. Taken together, these results suggested that OsBIC1 and OsCRYs worked together to regulate epidermal cell elongation and control blue light-induced leaf sheath elongation through the GA-responsive pathway.
\end{abstract}

Keywords: blue-light inhibitor of cryptochrome (BIC); cryptochrome (CRY); leaf sheath length; blue light; GA

\section{Introduction}

Cryptochromes are blue light receptors that regulate growth and development in plants [1]. In Arabidopsis thaliana, Cryptochrome 1 and 2 (CRY1 and CRY2) were first discovered to regulate hypocotyl elongation and flowering time, respectively [2-4]. CRY1 is the major blue light receptor that regulates hypocotyl elongation, whereas CRY2 mediates blue light-dependent hypocotyl elongation under low blue light intensity [1]. In the process of exploring cryptochrome signal transduction pathways and interaction proteins, two cryptochrome inhibitor proteins, Blue-light Inhibitor of Cryptochrome 1 and 2 (BIC1 and BIC2), have been found in Arabidopsis [5]. The latest research has proven that BIC1 inhibits the phenotype of CRY2 in regulating flowering time and hypocotyl elongation by suppressing the dimerization, phosphorylation, and degradation of CRY2 in a blue lightdependent manner [5-7]. Further investigation reveals that there is a CRY-BIC negative feedback loop to regulate blue light sensitivity in Arabidopsis [5-7]. All these results help us to elucidate the interaction mechanism between BIC and CRY in dicotyledonous plants. 
However, the function of BIC and the relationship between CRY and BIC in monocots plants have not been clarified.

Cryptochromes have been found throughout crop plants, including rice (Oryza sativa), but the regulation mechanism of CRY in crops is poorly understood [8-12]. Three genes in rice encode cryptochromes, referred to as OsCRY1a, OsCRY1b and OsCRY2 [13-15]. Previous studies show that OsCRY1a and OsCRY1b localize in the nucleus and cytoplasm. The overexpression of OsCRY1a, OsCRY1b and OsCRY2 result in shortened leaf sheath phenotype in rice [13]. In OsCRY2 RNAi plants, it was found that the down-regulation of OsCRY2 resulted in delayed flowering time in rice [14]. To find out how OsCRYs regulate leaf sheath length and flowering time in rice, Hirose et al. obtained the Oscry1b mutants from the Tos17 mutant library and constructed Oscry1a and Oscry 2 knockdown transgenic lines using RNA interference technology [15]. Further investigation displayed that OsCRY1 activated gibberellic acids (GAs) oxidase through a blue light signal to reduce the content of active gibberellin in rice [15]. GA is a phytohormone that regulates plant seed germination, stem elongation and flowering induction [16]. As shown previously, gibberellin acids, brassinosteroids (BR), and auxin are generally implicated in promoting hypocotyl elongation and determining plant height; nevertheless, this effect is inhibited during photomorphogenic development, demonstrating that phytohormones and light are antagonistic in regulating hypocotyl development [17-21]. Previous studies have revealed that cryptochromes inhibited blue light-induced hypocotyl elongation through the GAs metabolic pathway $[17,22-24]$. Blue light triggers the reduction in active gibberellin content and represses two gibberellin 20-oxidase genes (OsGA20ox2 and OsGA20ox4) and induces four gibberellin 2-oxidase genes (OsGA2ox4-OsGA2ox7) via OsCRY1a and OsCRY1b [24]. These results suggest that OsCRYs can regulate leaf sheath elongation through the GA response pathway, but whether other proteins are involved in this process is unclear. In the important dicotyledon crop soybean (Glycine max), seven cryptochrome proteins (GmCRYs, including GmCRY1a, GmCRY1b, GmCRY1c, GmCRY1d, GmCRY2a, GmCRY2b and GmCRY2c) have been identified and divided into two clades according to Arabidopsis CRY1 and CRY2, respectively. The studies in soybean show that GmCRYs involve in the regulation of photoperiodic flowering and leaf senescence [11,25]. Recent studies discovered that GmCRYs regulate stem elongation through crosstalk with the GA metabolic pathway [26]. All these results demonstrate that CRY can regulate plant growth through the GA-response pathway, but it is unclear whether CRY has the same function in monocotyledon plants and which proteins are involved in this process.

Here, we uncovered the function of OsBICs by analyzing the phenotype of the Osbic1 mutant, OsBIC1 and OsBIC2 overexpressing lines in rice. For the first time in monocotyledonous plants, we revealed the relationship of OsBICs and OsCRYs in regulating leaf sheath length using genetic analysis and improved the regulation mechanism of OsCRYs in regulating rice growth and development via the GA-response pathway.

\section{Results}

\subsection{OsBICs Promoted Leaf Sheath Elongation in Blue Light Specific Manner}

Using the homology alignment method, we successfully identified two genes homologous to Arabidopsis BIC1 and BIC2, referred to as OsBIC1 and OsBIC2. OsBIC1 locates on chromosome 4 and encodes a protein with 217 amino acid residues. OsBIC2 encodes a protein of 195 amino acid residues and is located on chromosome 2. To investigate the function of OsBIC1 and OsBIC2 in rice, we constructed the Pubi:OsBIC1-3Flag (OsBIC1OX) and Pubi:OsBIC2-3Flag (OsBIC2OX) overexpression vectors under the Maize ubiquitin 1 promoter (Pubi) and obtained multiple transgenic lines by Agrobacterium-mediated transformation. In total, 12 OsBIC1OXs and 9 OsBIC2Xs transgenic lines, which were verified by immunoblotting probed with an anti-Flag antibody, recapitulated for at least two generations demonstrating increased leaf sheath length phenotypes under blue light conditions. OsBIC1OX-3, OsBIC1OX-4, OsBIC2OX-6, and OsBIC2OX-7 overexpression lines expressed the same level of exogenous OsBIC1 or OsBIC2 proteins, so two independent overexpres- 
sion lines of both OsBIC1 and OsBIC2 (OsBIC1OX-4 and OsBIC2OX-7) were chosen for further experiments (Figure S1a). The respective overexpression of OsBIC1 and OsBIC2 in rice under the control of the Maize ubiquitin 1 promoter (Pubi) increased leaf sheath length in response to blue light (Figure $1 \mathrm{a}-\mathrm{c}$ ). Two independent loss-of-function lines of OsBIC1, Osbic1-1 and Osbic1-2, were obtained by CRISPR (clustered regularly interspaced short palindromic repeat)/Cas9-mediated genome-editing system (Figure S1b). DNA sequencing identified that both Osbic1-1 and Osbic1-2 contained a single base insertion in the first exon of OsBIC1, causing frameshifts and premature termination of protein translation (Figure S1b). Unfortunately, we did not obtain the Osbic2 mutant, probably due to the aberrant DNA structure or base's composition. Both Osbic1-1 and Osbic1-2 decreased the leaf sheath length under blue light conditions, so the Osbic1-2 mutant was chosen for further studies. OsBIC1OX-4, OsBIC2OX-7, and Osbic1-2 displayed opposite phenotypes in leaf sheath length under $2 \mu \mathrm{mol} \mathrm{m} \mathrm{m}^{-2} \mathrm{~s}^{-1}$ or $25 \mu \mathrm{mol} \mathrm{m}{ }^{-2} \mathrm{~s}^{-1}$ blue light conditions, and the leaf sheath length of the Osbic1 mutant was significantly shorter than that of WT, whereas the overexpression of OsBICs resulted in an obviously increased leaf sheath length phenotype (Figure $1 \mathrm{a}-\mathrm{c}$ ). To find out whether OsBIC1 and OsBIC2 respond to blue light specifically, WT, OsBIC1OX-4, OsBIC2OX-7, and Osbic1-2 were grown under dark, blue, red, and far-red light conditions for 14 days, respectively. Statistical analysis showed that the second leaf sheath length, third leaf sheath length, and seedlings total length of OsBIC1OX-4, OsBIC2OX-7, and Osbic1-2 displayed significant differences when compared with WT under blue light, but no differences were observed under continuous dark, red, and far-red light conditions, indicating that OsBICs promoted leaf sheath elongation in a blue light-specific manner (Figure 1d-f). To further confirm this result, WT, OsBIC1OX-4, OsBIC2OX-7, and Osbic1-2 were grown under blue light of different intensities, ranging from $0 \mu \mathrm{mol} \mathrm{m} \mathrm{m}^{-2} \mathrm{~s}^{-1}$ to $35 \mu \mathrm{mol} \mathrm{m} \mathrm{m}^{-2} \mathrm{~s}^{-1}$. Similar results showed that the second and third leaf sheath lengths of Osbic1-2 were significantly shorter than that of WT, whereas in OsBIC1OX-4 and OsBIC2OX-7, the second and third leaf sheaths were obviously longer than that of WT under all blue light intensity (low to high), demonstrating that OsBICs participated in the regulation of leaf sheath growth regardless of low blue light or high blue light conditions (Figure 1g-i). These results suggested that OsBIC1 and OsBIC2 promoted leaf sheath elongation in a blue light-specific manner.

\subsection{OsBIC1 Directly Interacted with OsCRYs to Regulate Blue Light-Induced Leaf Sheath Growth}

Previous studies in rice exhibit that the overexpression of OsCRYs (OsCRY1a, OsCRY1b, and OsCRY2) inhibited the leaf sheath growth under blue light conditions [13-15]. Combined with the research results in Arabidopsis, BIC1 inhibits the physical function of CRY2 via direct interaction [5,6]. We wondered whether OsCRYs and OsBICs work together to regulate leaf sheath length in rice. Oscry1a, Oscry1b, and Oscry2 mutants were constructed by the CRISPR/Cas9 system and identified through PCR and DNA sequencing (Figure S2a-c). Western blot showed that OsCRY1a and OsCRY2 proteins could not be detected in Oscry1a-2 and Oscry2-1 mutant lines, and OsCRY1b was partially reduced in the Oscry1b-1 mutant. The quantitative real-time polymerase chain reaction (qRT-PCR) result displayed that the expression of OsCRY1b reduced compared to WT (Figure S2d,e). Oscry1a-2 (1 bp deletion at the target 2 site), Oscry $1 b-1$ (4 bp deletion at the target 1 site), and Oscry2-1 (129 bp deletion at the target 1 site) mutants caused frameshifts and premature termination of protein translation and were chosen for further experiments (Figure S2). Oscry1a-2, Oscry1b-1, and Oscry2-1 exhibited a much longer leaf sheath than that of WT under blue-light $\left(0-35 \mu \mathrm{mol} \mathrm{m} \mathrm{m}^{-2} \mathrm{~s}^{-1}\right)$, and there were no obvious differences in leaf sheath between WT and Oscry1a-2, Oscry1b-1, and Oscry2-1 mutants under continuous dark, red, and far-red light conditions, confirming the former results that OsCRYs could repress the blue light-induced leaf sheath growth in rice (Figure S3). Moreover, Oscry1a-2 and Oscry1b-1 showed a much longer leaf sheath than Oscry2-1 under high blue-light intensity (above $15 \mu \mathrm{mol} \mathrm{m} \mathrm{m}^{-2} \mathrm{~s}^{-1}$ ), demonstrating that the contribution of OsCRY2 in blue light-induced leaf sheath growth inhibition was limited to a low light intensity range, while OsCRY1a and 
OsCRY1b were considered as the major blue light receptor regulating leaf sheath growth (Figure S3). Therefore, OsCRY1a and OsCRY2 were chosen for further experiments.

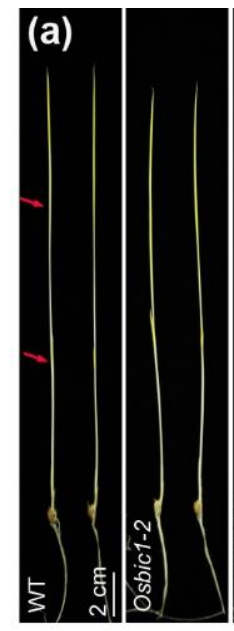

(d)

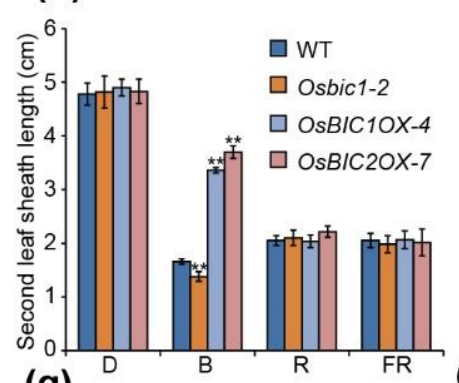

(g)
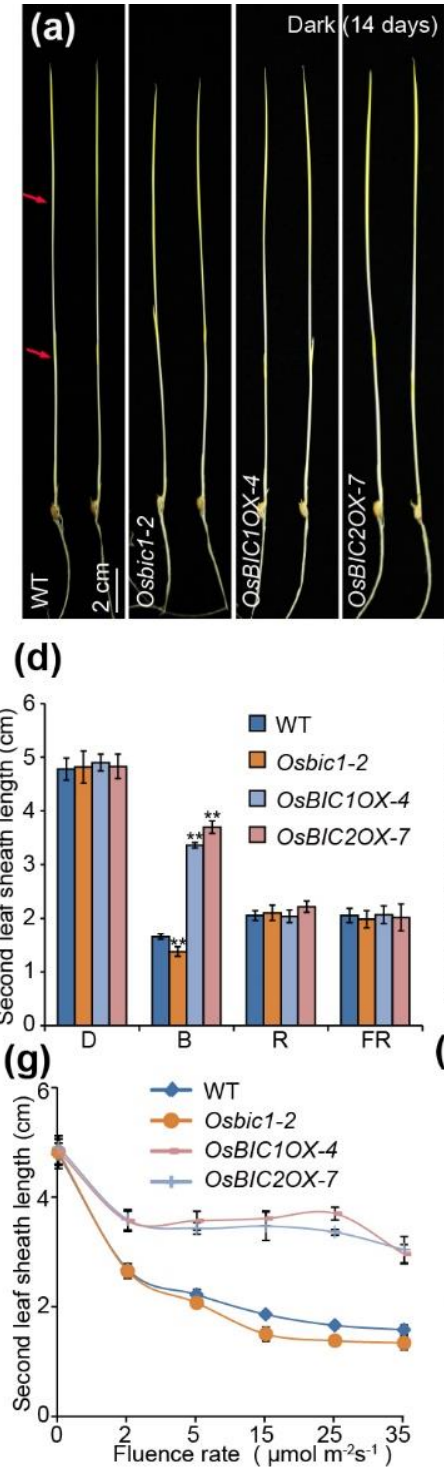

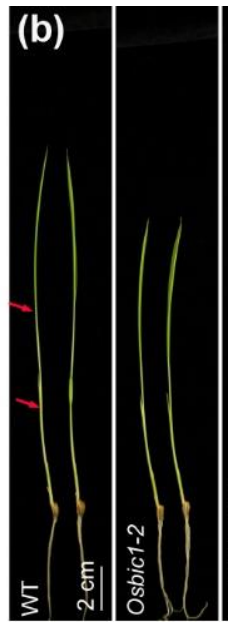

(e)
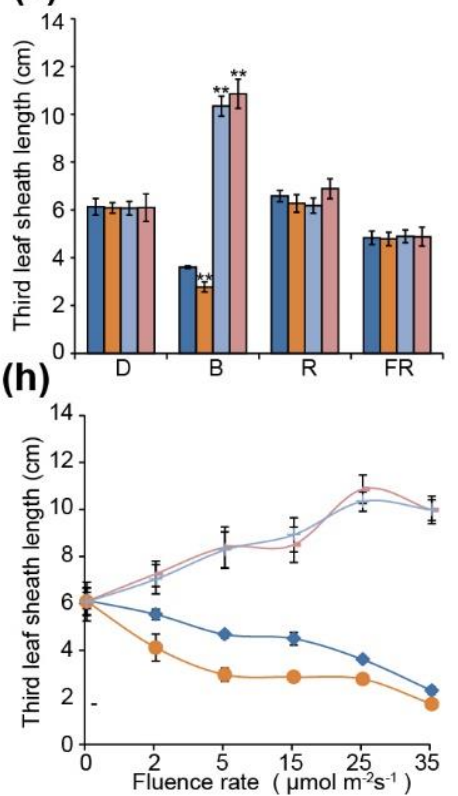

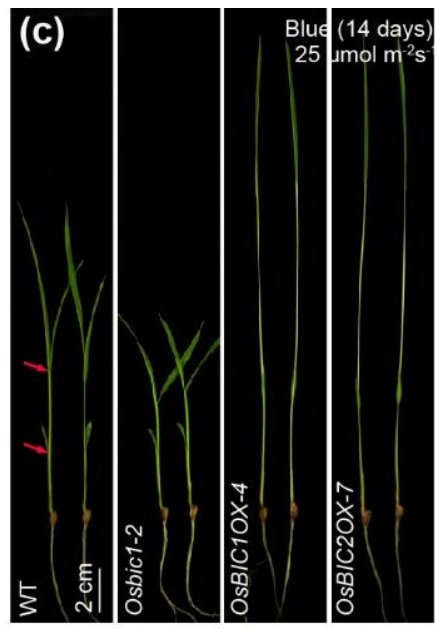

(f)
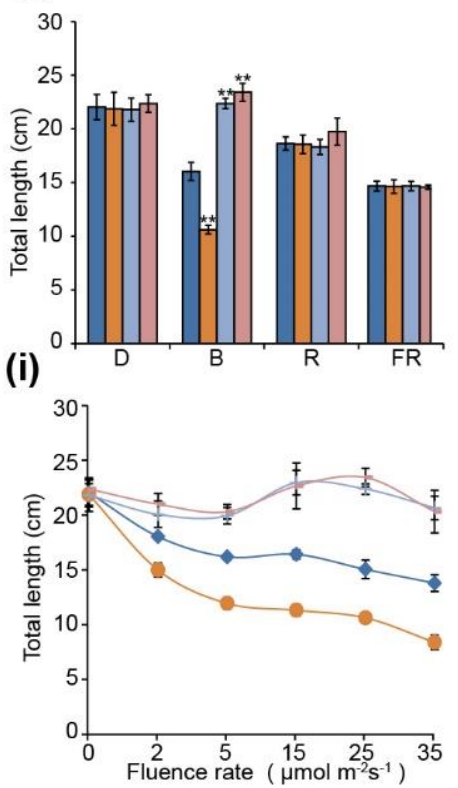

Figure 1. OsBICs (OsBIC1 and OsBIC2) promoted leaf sheath growth under blue light conditions. (a-c) Representative seedlings image of WT, Osbic1-2 mutant, and OsBICs overexpression lines (OsBIC1OX-4 and OsBIC2OX-7) grown under continuous dark (a), $2 \mu \mathrm{mol} \mathrm{m}{ }^{-2} \mathrm{~s}^{-1}$ blue light (b), and $25 \mu \mathrm{mol} \mathrm{m} \mathrm{s}^{-2} \mathrm{~s}^{-1}$ blue light (c) conditions at $28^{\circ} \mathrm{C}$ for 14 days. The red arrow represented the measured position of the second leaf sheath and the third leaf sheath. Scale bars $=2 \mathrm{~cm}$. (d-f) The statistics results of second leaf sheath length (d), third leaf sheath length (e), and total length (f) of 14 days old seedlings grown under continuous dark, blue light $\left(25 \mu \mathrm{mol} \mathrm{m}{ }^{-2} \mathrm{~s}^{-1}\right)$, red light $\left(25 \mu \mathrm{mol} \mathrm{m}^{-2} \mathrm{~s}^{-1}\right)$, or far-red light $\left(15 \mu \mathrm{mol} \mathrm{m}{ }^{-2} \mathrm{~s}^{-1}\right)$ conditions. Mean values \pm s.d. $(n=20)$ are shown. Comparisons were performed by Student's $t$-tests $(* * p<0.01)$. (g-i) The statistics results of second leaf sheath length $(\mathrm{g})$, third leaf sheath length (h), and total length (i) of 14 days old seedlings grown under continuous blue light with an intensity of 0 to $35 \mu \mathrm{mol} \mathrm{m}^{-2} \mathrm{~s}^{-1}$. Kita-ake wild-type plants (WT) were used as control.

In order to investigate the genetic relationship between OsBIC1 and OsCRYs, Osbic1Oscry1a and Osbic1Oscry2 double mutants were generated via crossing Osbic1-2 with Oscry1a-2 and Oscry2-1, respectively. The Osbic1Oscry1a and Osbic1Oscry2 double mutants displayed long leaf sheath phenotypes compared with WT and Osbic1-2 under 
$35 \mu \mathrm{mol} \mathrm{m}{ }^{-2} \mathrm{~s}^{-1}$ blue light conditions (Figure 2a). Similar results were observed under the increasing intensity of blue light, ranging from $0 \mu \mathrm{mol} \mathrm{m}^{-2} \mathrm{~s}^{-1}$ to $35 \mu \mathrm{mol} \mathrm{m}{ }^{-2} \mathrm{~s}^{-1}$ (Figure 2b-d). Osbic1Oscry 2 had much more influence on leaf sheath length at a low blue light intensity similar to that of Oscry2-1 (below $10 \mu \mathrm{mol} \mathrm{m}^{-2} \mathrm{~s}^{-1}$ ) (Figure $2 \mathrm{~b}-\mathrm{d}$ ). These results indicated that OsCRY1a and OsCRY2 acted epistatically to OsBIC1, and OsCRY1a and OsCRY2 worked in the same pathway with OsBIC1 to regulate leaf sheath length. To further clarify the physical interaction between OsCRY1a, OsCRY1b, OsCRY2, and OsBIC1, we performed yeast two-hybrid assays, and the results revealed that OsBIC1 strongly interacted with OsCRY2 under blue light conditions, but the interaction between OsBIC1 with OsCRY1a and OsCRY1b appeared to be slightly weaker when compared with OsCRY2 (Figure 2e). Moreover, OsBIC2 could interact with the OsCRYs protein under both dark and blue conditions (Figure S4). To further confirm this result, we checked the interaction between OsBICs and OsCRYs in vivo by firefly luciferase complementation imaging (LCI) assays. The $p$ Cambia-35S:OsBICs-LUCN $\left(\mathrm{OsBIC1}-L U C^{N}{ }^{N}\right.$ OsBIC2-LUC $\left.{ }^{N}\right)$ and pCambia-35S:OsCRYs-LUC ${ }^{C}$ (OsCRY1a-LUC $C^{C}$, OsCRY1b-LUCC $C^{C}$ OsCRY2-LUC ${ }^{C}$ ) plasmids were co-transformed into Nicotiana benthamiana leaves, respectively. Luminescence was observed in all the combinations containing OsBIC1 and OsCRYs (Figure 2f). The LCI assays results confirmed the physical interaction between OsBICs and OsCRYs in Nicotiana benthamiana (Figure $2 \mathrm{f}$ and Figure S4). These results indicated that OsBIC1 physically interacted with OsCRYs in a blue light intensity-dependent manner, while OsBIC2 interacted with OsCRYs in a blue light intensity-independent manner (Figure 2 and Figure S4). Taken together, we concluded that OsBICs and OsCRYs influenced leaf sheath length through direct interaction. Considering the opposite phenotype of leaf sheath length between OsBICs and OsCRYs, we speculated that OsBICs inhibited the function OsCRYs in leaf sheath length regulation via interaction directly.

\subsection{OsBIC1 and OsCRYs Regulated Leaf Sheath Length by Regulating Epidermal Cell Length}

To find out the reasons that caused the differences in leaf sheath length, we performed longitudinal sections histological analysis. WT and each indicated mutant were grown under continuous blue light conditions at $28^{\circ} \mathrm{C}$ for 14 days $\left(35 \mu \mathrm{mol} \mathrm{m}^{-2} \mathrm{~s}^{-1}\right)$. The complete second leaf sheaths were collected and used for longitudinal sections histological analysis. Interestingly, while observing epidermal cell length, we found that the epidermal cells of the second leaf sheath gradually lengthen from bottom to top, showing a gradient in length, ranging from 10 to $50 \mu \mathrm{m}$ (Figure 3a). Therefore, to better understand the regularity of cell length in each genotype, we divided the epidermal cells into five different groups according to the cell length: 0-15 $\mu \mathrm{m}, 15-20 \mu \mathrm{m}, 20-30 \mu \mathrm{m}, 30-40 \mu \mathrm{m}$, and $40-50 \mu \mathrm{m}$ (Figure 3a, middle panel and right panel). Then, we calculated and compared the cell number in different groups and plotted the percentage of cell numbers in each group between WT and each indicated mutants (Figure 3e). The percentage results showed that Oscry1a-2, Oscry2-1, Osbic1Oscry1a, and Osbic1Oscry2 showed a decrease in cell number with cell length less than $15 \mu \mathrm{m}$ and an increase in cell number with a length more than $20 \mu \mathrm{m}$ when compared with WT (Figure 3d,e). The number of epidermal cells less than $15 \mu \mathrm{m}$ in Osbic1-2 increased obviously, while cell number in cell length more than $20 \mu \mathrm{m}$ decreased greatly in Osbic1-2 compared with WT and other indicated mutants (Figure 3e). Subsequently, we calculated the cell number of the outermost epidermal cells in WT and each indicated mutant. Similar to our prior results, the second leaf sheath length of WT was on average longer than that of Osbic1-2 and shorter than that of Oscry1a-2, Oscry2-1, Osbic1Oscry1a, and Osbic1Oscry2 (Figure 3b). The cell number of the outermost epidermal cells showed no obvious differences in Oscry1a-2, Oscry2-1, Osbic1Oscry1a, and Osbic1Oscry2 when compared with WT, and only a slight decrease in cell number was observed in Osbic1-2 (Figure 3c). Taken together, these results suggested that longer cell length made more contribution on increasing leaf sheath length in Oscry1a-2, Oscry2-1, Osbic1Oscry1a, and Osbic1Oscry2 plants, the shorter sheath length in Osbic1-2 is attributed to a greater proportion of epidermal cells smaller than $15 \mu \mathrm{m}$, consolidating that OsBIC1 
and $O s C R Y s$ controlled leaf sheath length through influencing the ratio of epidermal cells with different lengths.
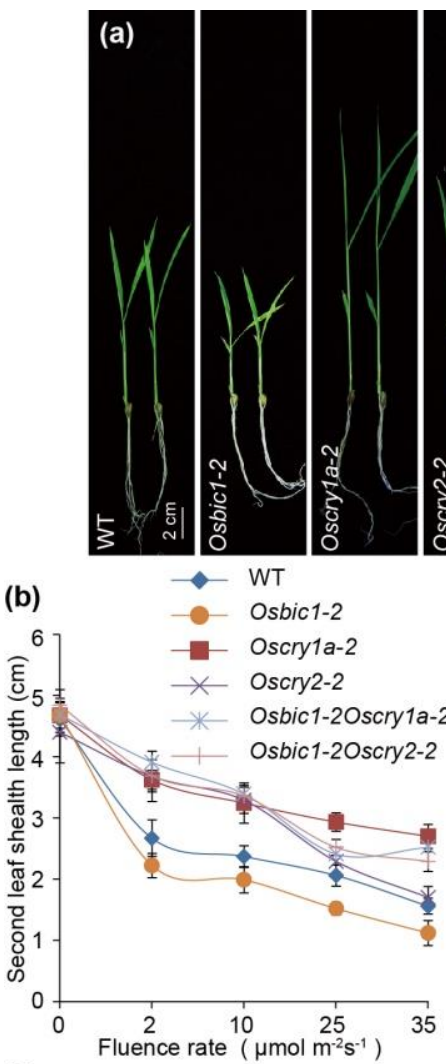

(f)

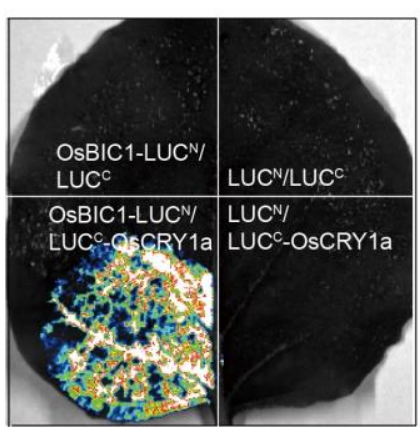

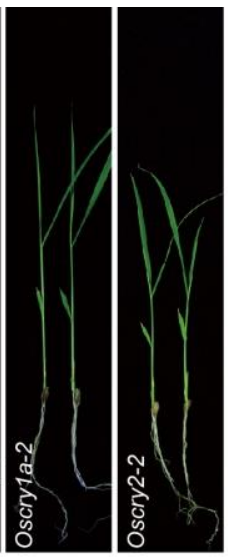

(c)
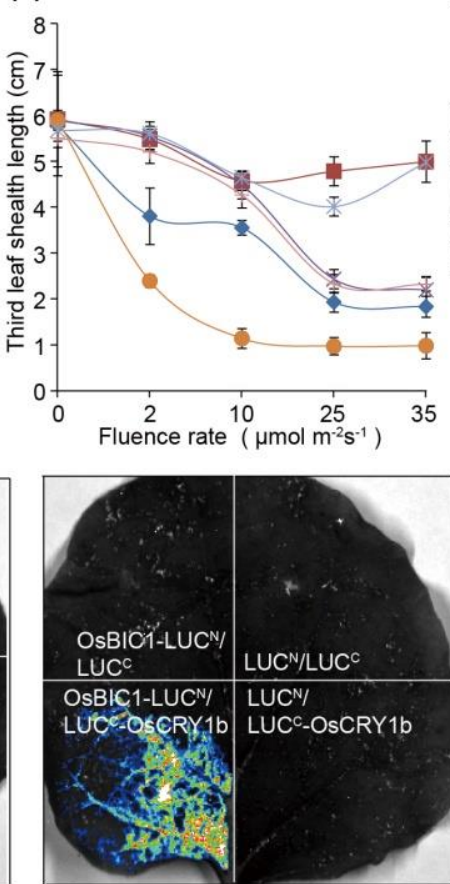

(e)

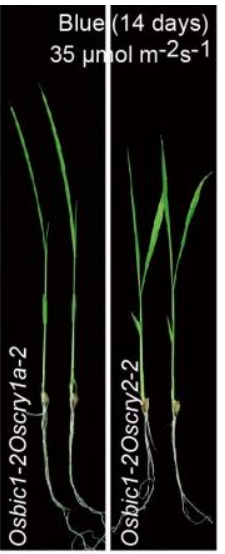

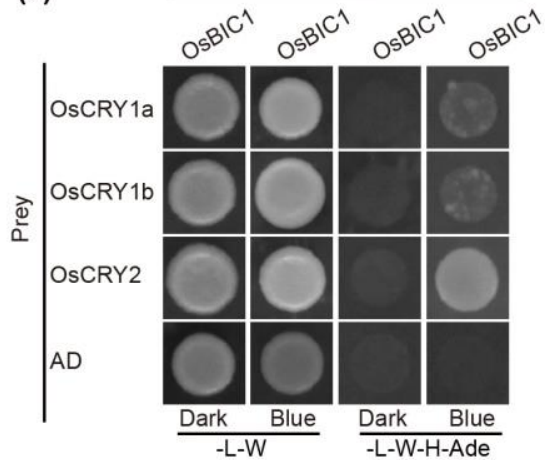

(d)
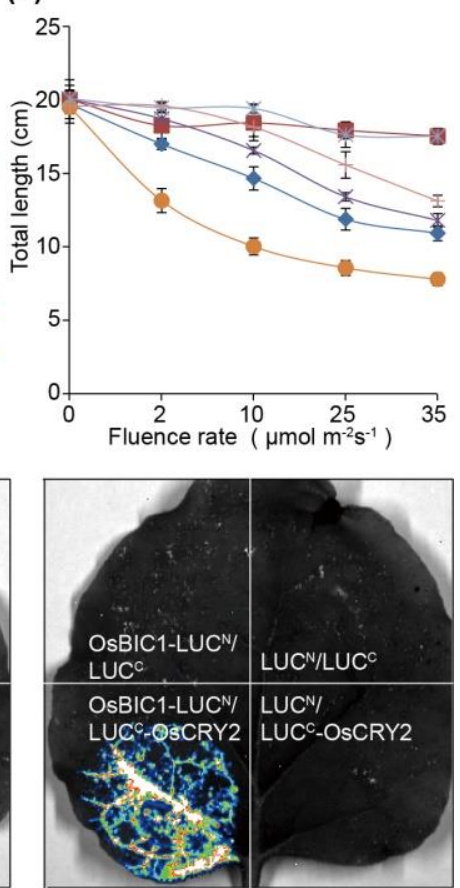

Figure 2. OsBIC1 directly interacted with OsCRYs (OsCRY1a, OsCRY1b, and OsCRY2) to control leaf sheath length under blue light conditions. (a) Representative seedlings image of WT and each indicated mutants grown under continuous $35 \mu \mathrm{mol} \mathrm{m}{ }^{-2} \mathrm{~s}^{-1}$ blue light conditions at $28{ }^{\circ} \mathrm{C}$ for 14 days. Scale bars $=2 \mathrm{~cm}$. (b-d) The statistics results of second leaf sheath length (b), third leaf sheath length (c), and total length (d) of 14 days old seedlings grown under continuous blue light with intensity of 0 to $35 \mu \mathrm{mol} \mathrm{m} \mathrm{m}^{-2} \mathrm{~s}^{-1}$. Mean values \pm s.d. $(n=20)$ are shown. (e) OsBIC1 interacted with OsCRYs in yeast two-hybrid assays. Empty vector expressing the AD domain was negative control. (f) Interaction between OsBIC1 and OsCRYs under long day conditions in LCI assays.

\subsection{OsBIC1 and OsCRY1s Regulated Similar Transcriptome Changes under Blue Light Conditions}

To investigate the mechanism of OsBIC1 and OsCRYs in regulating cell elongation, the Oscry1aOscry1b (Oscry1s) double mutant was generated via crossing Oscry1a-2 and Oscry $1 b-1$, and the etiolated seedlings of WT, Osbic1, Oscry1s were kept in the dark (dark treatment, WT-Dark, Osbic1-Dark, and Oscry1s-Dark) or exposed to blue light $2 \mathrm{~h}$ (blue light treatment, WT-Blue, Osbic1-Blue, and Oscry1s-Blue) to conduct high-throughput RNA-sequencing assays. Compared with WT-dark, 1793 differentially expressed genes 
(Fold Change $(\mathrm{FC})>2, p$ value $<0.01$, and False Discovery Rate $(\mathrm{FDR})<0.01$ ) were identified in the WT-Blue plants and defined as blue light-regulated genes, in which 1286 and 507 genes were up- and down-regulated, respectively (Figure 4a). Out of the 1793 blue light-regulated genes, 1589 were not differentially expressed in Oscry1s-Blue plants when compared with Oscry1s-Dark and defined as OsCRY1a and OsCRY1b (OsCRY1s)-regulated genes (FC $<2$ or $p>0.01$ ) (Figure 4a). Out of 1793 blue light-regulated genes, 725 were differentially expressed in the Osbic1-blue plants when compared with Osbic1-dark, and named as OsBIC1-regulated genes (FC $>2, p$ value $<0.01$, and FDR $<0.01$ ) (Figure 4a). Venn diagram analysis showed that 592 candidate genes were detected in the overlapping profiles among blue light-regulated, OsCRY1s-regulated, and OsBIC1-regulated genes, defined as OsCRY1s and OsBIC1-regulated (CB-reg) genes (Figure 4a). Then we performed hierarchical clustering analysis of the CB-reg genes and found that 386 OsCRY1s and OsBIC1-regulated genes were up-regulated, and 206 genes were down-regulated in WT and Osbic1-2 in response to blue light (Figure 4b). Then, we analyzed the correlation between OsCRY1s and OsBIC1 regulated genes by using scatter plots analysis. The red dots represented up-regulation CB-reg genes, and green dots indicated down-regulation $\mathrm{CB}$-reg genes. The purple and blue dots represented up-regulation or down-regulation genes that were not co-regulated by OsCRY1s and OsBIC1 (Non-CB-reg) (Figure 4c). Taken together, nearly $82 \%$ (592 out of 725 ) of the OsBIC1-regulated genes were also regulated by $O s C R Y 1$, demonstrating that $O s B I C 1$ and $O s C R Y 1$ s regulated similar transcriptome changes under blue light conditions and OsBIC1 controlled blue light-induced leaf sheath growth dependent on OsCRY1s (Figure 4a-c). To further investigate the genetic regulatory pathway associated with the leaf sheath growth in the Osbic1-2 and Oscry1s plants, gene ontology (GO) was used to analyze the blue light-regulated, OsCRY1s-regulated, OsBIC1regulated, and OsCRY1s and OsBIC1-regulated genes. GO analysis revealed that genes regulated by OsBIC1 and OsCRY1s in response to blue light were mainly enriched in the pathways related to response to blue light, red light, high light intensity, seed germination and so on, indicating that OsBIC1 and OsCRY1s were closely related to light response (Figure 4d). It was important to note that the genes were also enriched in the gibberellin metabolic process, gibberellic acid-mediated signaling pathway, gibberellin biosynthetic process, auxin biosynthetic process, and brassinosteroid metabolic process (Figure 4d). GA increases rice internode length by promoting cell division and cell elongation in rice, suggesting that OsBIC1 and OsCRY1s are involved in the regulation pathway of the hormone in rice, especially GA (Figure $4 \mathrm{~d}$ ).

\subsection{OsBIC1 and OsCRYs Regulated Leaf Sheath Length through the GA-Responsive Pathway}

In our RNA sequencing results, a series of genes related to gibberellin metabolism, gibberellin biosynthesis, and gibberellin signal transduction were differentially expressed when the etiolated seedlings of WT were exposed to blue light (Figure S5). Consistent with previous studies, quantitative reverse transcription-polymerase chain reactions (qRTPCR) results showed that most gibberellin biosynthetic genes (OsGA20ox2, OsGA3ox2, and $\mathrm{OsKO2}$ ) were down-regulated in response to blue light, while gibberellin metabolic gene (OsGA2ox6 and OsGA2ox7) and gibberellic acid-mediated signaling genes (OsbZIP18 and OsbZIP48) were both up-regulated (Figures S5 and S6) [24]. To confirm whether OsBIC1 and OsCRY1s could participate in the GA regulation pathway, we firstly examined the endogenous bioactive levels of GAs (total GA content, GA1 content and GA3 content) in WT and indicated mutants. The total GA, GA1, and GA3 content significantly increased in Oscry1a-2, Oscry2-1, Osbic1Oscry1a, and Osbic1Oscry2, whereas drastically reduced in Osbic1-2 compared with WT under blue light conditions, suggesting that OsBIC1 and OsCRY1s involved in the regulation of GA pathway (Figure 5a-c). 


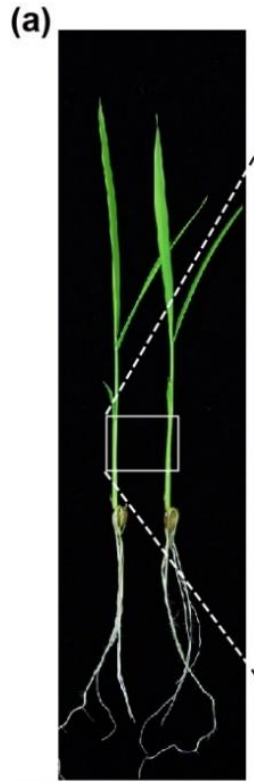

(b)

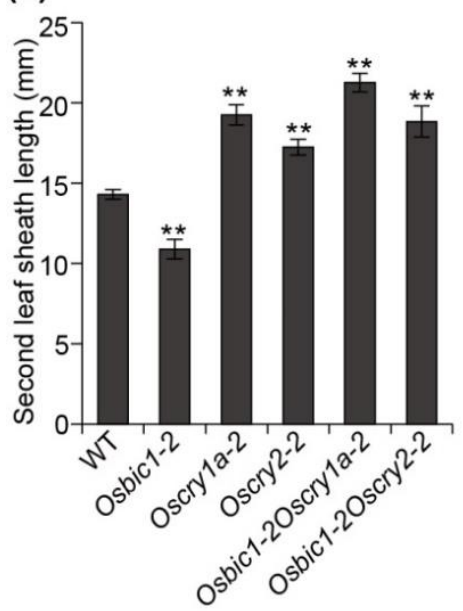

$40<$ Cell length $<50(\mu \mathrm{m})$

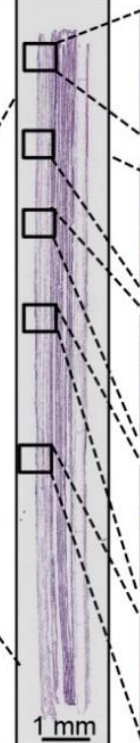

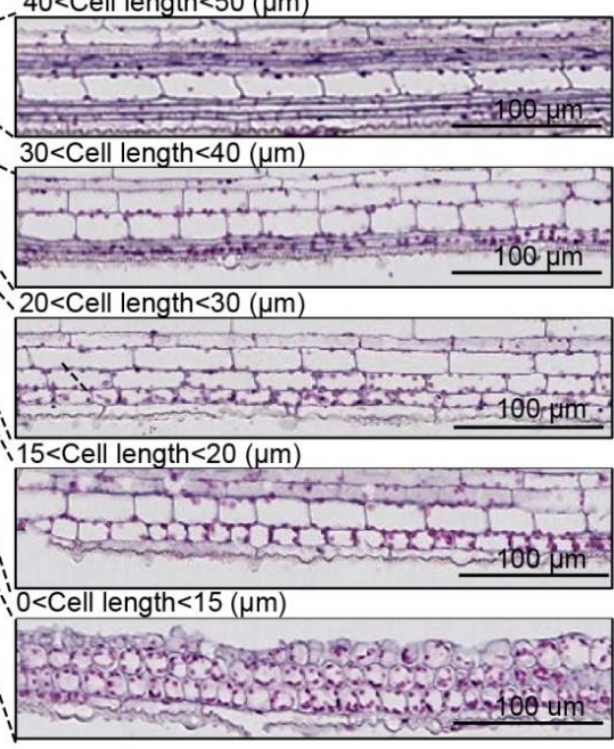

(c)

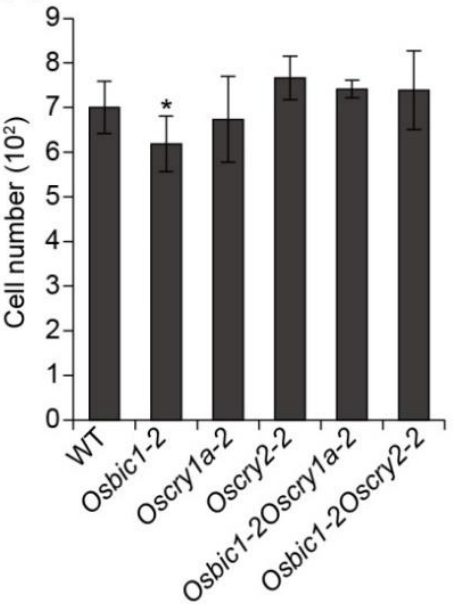

(e) $\square 0<$ Cell length $<15(\mu \mathrm{m})$

$\square 15<$ Cell length $<20(\mu \mathrm{m})$

$\square 20<$ Cell length $<30(\mu \mathrm{m})$

$\square 30<$ Cell length $<40(\mu \mathrm{m})$

$\square 40<$ Cell length $<50(\mu \mathrm{m})$
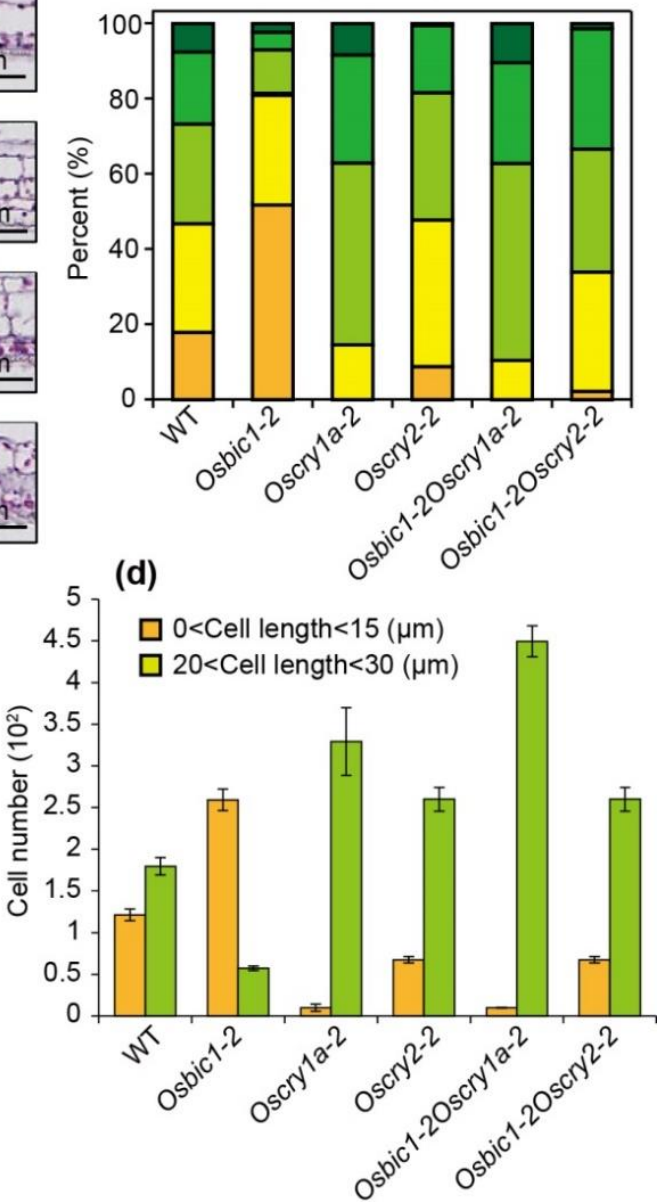

Figure 3. OsBIC1 and OsCRYs controlled the cell elongation in response to blue light. (a) Two seedlings of WT to show the position of the second leaf sheath ((a) left panel). The epidermal cells were divided into five groups according to the cell length: 0-15 $\mu \mathrm{m}, 15-20 \mu \mathrm{m}, 20-30 \mu \mathrm{m}, 30-40 \mu \mathrm{m}$, and 40-50 $\mu \mathrm{m}$ ((a) middle panel and right panel). (b-d) Comparisons of the second leaf sheath length (b), cell number of the outermost epidermal cells (c), and cell numbers of the outermost epidermal cells of 0-15 $\mu \mathrm{m}$ and 20-30 $\mu \mathrm{m}$ in length (d) analysis between WT and each indicated mutants. (e) Comparison of the percentage of cell number in different groups between WT and each indicated mutants. Mean values \pm s.d. $(n=10)$ are shown. Comparisons were performed by Student's $t$-tests $\left({ }^{*} p<0.05,{ }^{* *} p<0.01\right)$.

To elucidate the molecular mechanism of OsBIC1 and OsCRYs in controlling GAresponsive pathway, we conducted qRT-PCR to test the GA-responsive gene in WT and each indicated mutant. The transcriptional expression of the GA-responsive genes displayed no significant differences between WT and each indicated mutant under dark conditions, whereas significant change was discovered under blue light conditions (Figure $5 \mathrm{~d}-\mathrm{i}$ ). The OsGA20ox2 (SD1) and OsKO2 (D35) loss of function mutants exhibit remarkable dwarf or semi-dwarf phenotypes caused by a defective early step of gibberellin biosynthesis [27-30]. The expression of OsGA20ox2 and OsKO2 were up-regulated in Oscry1a-2 and Oscry2-1 compared with WT, whereas down-regulated in Osbic1-2 (Figure 5d,e). Contrary to the GA biosynthetic genes, the transcription levels of GA catabolic genes OsGA2ox6 and OsGA2ox7 in Oscry1a-2 and Oscry2-1 significantly reduced (Figure 5f,g) [16,31,32]. GA-mediated 
signaling genes play an important role in the regulation of plant height growth $[20,33,34]$. OsbZIP18 and OsbZIP48 are the AtHY5 transcription factor homologs in rice, and the overexpression of OsbZIP48 leads to semi-dwarf phenotypes by being involved in the regulation of GA biosynthesis and signaling [35]. The expression of OsbZIP18 and OsbZIP48 were down-regulated in Oscry1a-2 and Oscry2-1, whereas it was up-regulated in Osbic1-2 mutant (Figure 5h,i).

(a)

Blue light-Regulated Genes (1793)

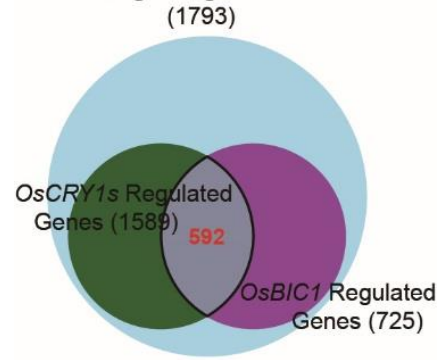

OsCRY1s and OsBIC1 Regulated

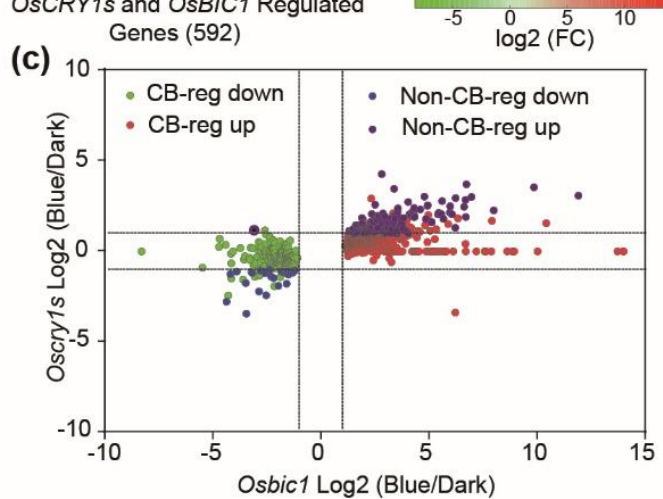

(b)
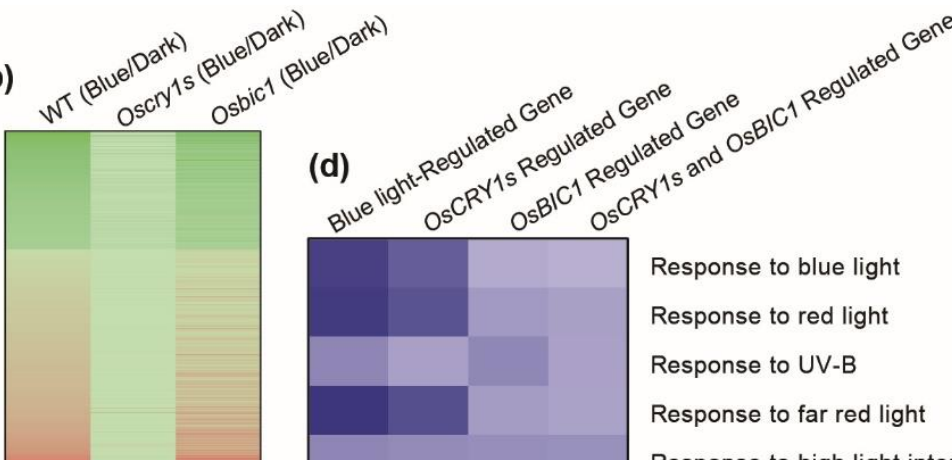

Response to high light intensity

Photosynthesis, light reaction

Response to temperature stimulus

Seed germination

Gibberellin metabolic process

Gibberellic acid mediated signaling pathway

Gibberellin biosynthetic process

Auxin biosynthetic process

Brassinosteroid metabolic process

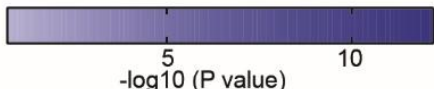

Figure 4. OsBIC1 and OsCRY1s regulated similar transcriptome changes under blue light conditions. (a) Venn diagram depicting the overlapping profiles among blue light-regulated, OsCRY1s-regulated, OsBIC1-regulated, and OsCRY1s and OsBIC1-regulated genes determined by RNA-seq. Blue lightregulated genes showed a factor of $>2$ change of mRNA (Fold Change (FC) $>2, p$ value $<0.01$, False Discovery Rate (FDR) < 0.01) in WT-Blue when compared with WT-Dark. The blue light-regulated genes that showed FC $<2$ or $p>0.01$ in Oscry1s-Blue in comparison to Oscry1s-Dark were defined as OsCRY1s-regulated genes. The blue light-regulated genes that showed FC $>2$ and $p<0.01$ in Osbic1Blue in comparison to Osbic1-Dark were defined as OsBIC1-regulated genes. The overlapping profiles among blue light-regulated, OsCRY1s-regulated, and OsBIC1-regulated genes were defined as CB-reg genes. (b) Hierarchical clustering analysis of the CB-reg genes in blue light-regulated, OsCRY1sregulated, and OsBIC1-regulated genes profiles. Green indicated down-regulation genes, and red was used to indicate up-regulation genes. (c) Scatter plots show the correlation between the Osbic1 blue/dark $\log 2$ (FC) and Oscry1s blue/dark log2 (FC). The dashed lines indicated log2 (FC) = 1 and -1. (d) Enriched gene ontology functional categories in the blue light-regulated, OsCRY1s-regulated, OsBIC1-regulated, and OsCRY1s and OsBIC1-regulated genes. 
(a)
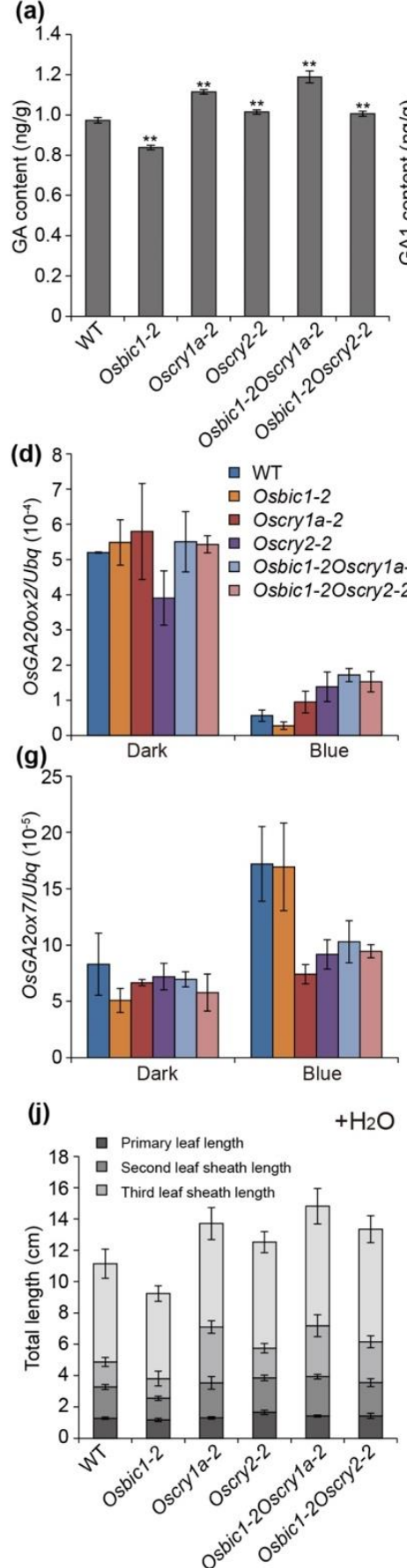

(b)

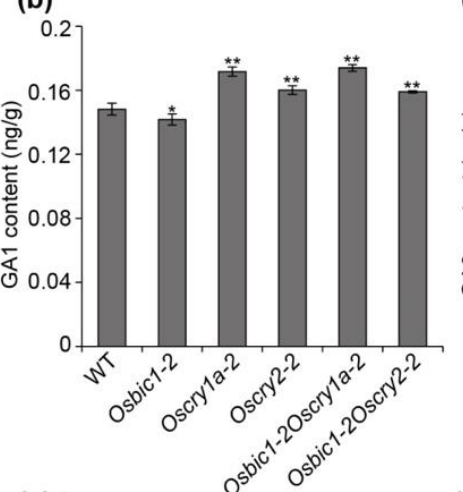

(e) 9
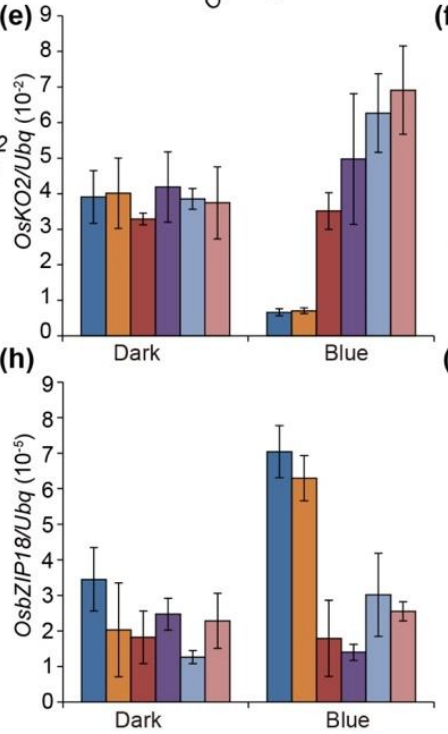

(k)

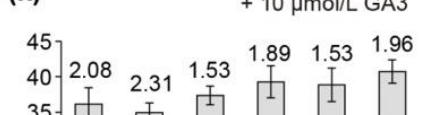

(c)
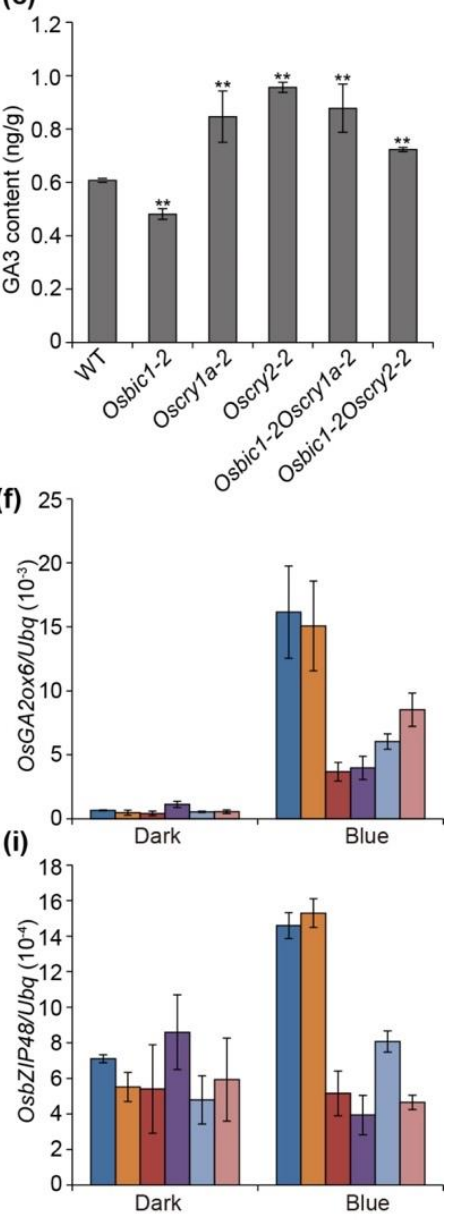

(l)

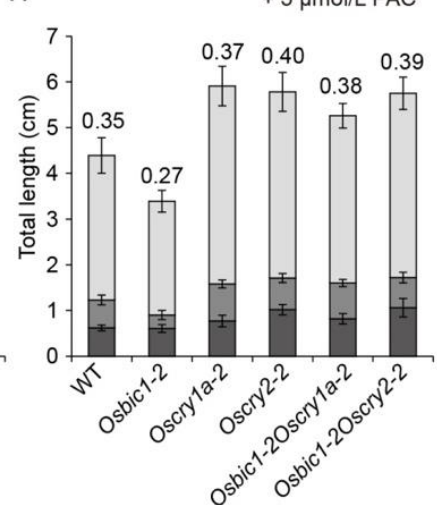

Figure 5. OsBIC1 and OsCRYs regulated the gibberellic acid (GA)-responsive gene expression under blue light conditions. (a-c) The GA, GA1, and GA3 content of seven-day-old seedlings grown in continuous blue light conditions $\left(25 \mu \mathrm{mol} \mathrm{m}{ }^{-2} \mathrm{~s}^{-1}\right)$. Comparisons were performed by Student's $t$-tests $\left({ }^{*} p<0.05,{ }^{* *} p<0.01\right)$. (d-i) Comparisons of transcription levels of GA-responsive gene using qRT-PCR between WT and each indicated mutants. The relative expression levels (REL) are shown as means \pm s.d. $(n=3)$. Ubiquitin $(U b q)$ was used as an internal control, and the REL of the WT sample in the dark was arbitrarily set to 1 . (j-1) Comparisons of leaf sheath length between WT and each indicated mutants in response to GA3 or Paclobutrazol (PAC). The leaf sheath length analyses of 14 days old seedlings grown under continuous $35 \mu \mathrm{mol} \mathrm{m}^{-2} \mathrm{~s}^{-1}$ blue light. The number on the column indicated sensitivity to GA3 or PAC. Each number on the plot represented leaf sheath elongation ratio, which was equal to leaf sheath length under GA3 or PAC treatments divided by leaf sheath length treated with water. 
In addition, we also found that Oscry1a-2 and Oscry2-1 exhibited a slightly lower leaf sheath elongation ratio compared with WT, after exogenous $10 \mu \mathrm{mol} / \mathrm{L}$ GA3 treatment (Figure 5k). However, Osbic1-2 showed significantly more sensitive responsiveness to GA3 than WT. Meanwhile, after exogenous $5 \mu \mathrm{mol} / \mathrm{L}$ Paclobutrazol (PAC) treatments, the leaf sheath elongation ratio in WT was slightly higher than that of Osbic1-2 and lower than that of Oscry1a-2 and Oscry2-1 (Figure 51). Osbic1Oscry1a and Osbic1Oscry2 displayed similar results compared with Oscry1a-2 and Oscry2-1, respectively (Figure 5j-1). It was worth noting that regardless of GA3 or PAC treatment, Oscrys and Osbic1 always exhibited a difference in the phases of leaf sheath growth compared with WT, suggesting that OsBIC1 and $O s C R Y s$ were essential for GA response and could participate in the regulation of GA signaling. These results indicated that OsBIC1 and OsCRYs worked together in the same GA-responsive pathway and OsCRYs acted epistatically to OsBIC1.

\section{Discussion}

BICs are newly identified nuclear proteins and widely found in moss, gymnosperm, and angiosperm that can directly interact with CRYs to inhibit their function by blocking blue light-dependent cryptochrome dimerization [5]. BICs are induced by blue light, and the overexpression transgenic lines exhibit similar phenotypes resembling that of the cry1cry 2 mutant, including blue light-insensitive hypocotyl growth and delayed floral initiation in long-day (LD) photoperiod [5,6,36]. The function of BICs in rice or other crops is largely unknown. Here, we reported that there were two OsBICs nuclear proteins in rice, which contained a conserved CRY-interacting domain (CID) in the C-terminal region, and the transcriptional expression of OsBICs were induced by blue, red, and far-red light (Figures S5 and S6). OsBICs overexpression transgenic lines exhibited significantly blue light promotion of leaf sheath growth phenotypes, while the leaf sheath phenotype of the Osbic1 mutant was contrary to the overexpression of OsBICs (Figure 1). Further studies showed that OsBICs inhibited the function of OsCRYs in regulating leaf sheath growth by interacting with OsCRYs proteins (Figures 2 and 3). To summarize, there were many similarities between OsBICs and Arabidopsis BICs in terms of protein conservative domains, blue light-induced expression, subcellular localization, and the regulation of blue light-induced leaf sheath growth, suggesting that BICs are widely distributed in the plant, exhibited a conservative trend during biological evolution and might be involved in a similar function in other crops.

Plant height is an important character determined plant architecture, yield and stress response in rice and is controlled by phytohormones and their integrated signaling networks [37]. Gibberellins (GAs) increase plant height through mediating cell division and cell elongation in rice, and GA-deficient or GA-insensitive mutants display a dwarf or semidwarf phenotype [30]. Several GA biosynthesis, metabolic, and signaling-related genes have been identified to involve in the regulation of plant height, organ development, yield and stress response in rice, including OsGA20ox2, OsGA3ox2, OsKO2, OsGA2ox6, SLR1, and GID1 [27-29,38,39]. The latest research suggests that cryptochrome and phytochrome cooperatively but independently rapidly decrease gibberellin activity in rice following light irradiation $[17,22,24]$. Consistent with previous results, here, we discovered that OsBIC1 and OsCRYs regulated cell elongation by changing the content of active gibberellin through mediating the transcript level of gibberellin biosynthesis and metabolic genes, and the expressions of OsGA20ox2, OsKO2, OsGA2ox6, and OsGA2ox7 were changed in each indicated mutant under blue light conditions (Figure 5, Figures S5 and S6). Gibberellins are primarily synthesized in actively growing and elongation tissues, OsGA20ox2, OsGA3ox2, and SLR1 are highly expressed in inflorescence meristems [40]. Previous results show that Cytokinins (CKs) and GAs are antagonistic to regulate meristem activity [41]. The dynamic balance among auxin, GAs, and CKs determines meristem activity in inflorescence [42]. When OsBIC1OX and OsBIC2OX overexpression lines transited from the vegetative growth stage to the reproductive growth stage, both transgene lines showed taller, later-flowering, and wider leaf phenotypes compared with wild type (unpublished data). We speculated 
that these phenotypes might be related to the regulation of meristem activity by GA. The expression of OsGA20ox2 and OsKO2 increased under blue light in Oscry1a-2, Oscry2-1, Osbic1Oscry1a, and Osbic1Oscry 2 mutants compared with WT (Figure 5d,e), which might enhance the meristem activity and lead to the phenotype changing, such as leaf color and thickness. The overexpression of OsBIC1OX and OsBIC2OX inhibited the function of OsCRY1 and produced a phenotype similar to Oscry1a-2, Oscry2-1, Osbic1Oscry1a, and Osbic1Oscry2, which displayed an opposite phenotype to Osbic1 (Figure 2 and Figure S3). These results will provide new ideas for us to study the regulation of meristem activity by blue light.

OsbZIP48, an HY5 Transcription Factor orthologue, directly binds to the promoter of $\mathrm{OsKO} 2$ through a G-Box element and involves in GA biosynthesis in rice. The overexpression of OsbZIP48 can significantly inhibit the expression of OsGA20ox2 and OsKO2 [35]. In our study, we found that the transcript level of OsbZIP48 was down-regulated in Oscry1a-2 and Oscry2-1 mutants, whereas up-regulated in Osbic1-2 mutant under blue light conditions, suggesting that OsBIC1 and OsCRYs may regulate GA biosynthesis through the OsbZIP48 gene in blue light (Figure 5). In the meanwhile, combining the previous conclusions, which was that the HY5 of P. satioum binds to the promoter of GA catabolism gene GA2ox2 to promote its expression, in Arabidopsis, AtHY5 binds to the promoter of AtGA2ox2 and participates in the regulation of the gibberellin metabolism $[43,44]$. Two CACGTG motifs in the OsGA2ox6 promoter region (-104 and -2336) and four CACGTG motifs in the OsGA2ox7 $(+624,+1326,+1937$ and +2863$)$ genomic region were identified, speculating that OsbZIP48 might directly bind to OsGA2ox6 and OsGA2ox7 genes to increase their expression. OsBIC1 and $O s C R Y s$ may also control GA metabolic program through the OsbZIP48 gene in blue light, which needs further study.

OsbZIP48 involves in the GA signaling pathway by down-regulated the expression of OsSLR1, OsSLRL1, OsGID1, and OsGID2, which are central repressors or positive regulators of GA signaling $[35,45]$. The rice slender mutant (slr1-1) results in a constitutive gibberellin response phenotype and has very rapid extension growth in the seedling and is sterile [46]. GID1 protein acts as a positive regulator of gibberellin signaling, and the GA-insensitive dwarf mutant of rice (gid1) cannot respond to gibberellin [20]. Moreover, GID1 protein can specifically bind radiolabeled gibberellin and that GID1 binding to SLR1 is gibberellindependent [20]. However, OsBIC1 and OsCRYs could not influence the expression of OsSLR1, OsSLRL1, OsGID1, and OSGID2 in our experiment (Table S2), demonstrating that GA signaling genes (OsSLR1, OsSLRL1, OsGID1 and OSGID2) were not controlled by blue light at the transcriptional level and OsbZIP48 had no obvious effect on the GA signaling genes under blue light conditions (Table S2). Recent studies show that DELLA proteins, central repressors in GA signaling, are ubiquitinated by COP1 in vitro through physically interacting with COP1, which are enhanced by the COP1-SPA1 complex, suggesting that DELLA proteins are destabilized not only by the canonical GA-dependent pathway but also by COP1 [47]. In the CRYs signal transduction pathway, CRY1 physically interacts with SPA1 in a blue-light-dependent manner, and the CRY1-SPA1 interaction negatively regulates COP1 by promoting the dissociation of COP1 from SPA1 in Arabidopsis [48-51]. CRY2 also interacts with SPA1 under blue light conditions to suppress COP1-dependent proteolysis through stimulating the CRY2-COP1 interaction in Arabidopsis [52-54]. In rice, OsCRY1b can interact with OsCOP1 to regulate leaf sheath and flowering time in rice through the OsCOP1 pathway [15]. Our GA3 or PAC treatment experiments indicated that OsBIC1 and $O s C R Y s$ were essential for GA response and could participate in the regulation of GA signaling (Figure 5). Based on the above results, we speculate that OsBIC1 and OsCRYs were considered to participate in the GA signaling pathway at the protein level through the COP1-SPA1 complex. All these speculations need to be further proofed. 


\section{Materials and Methods}

\subsection{Primers and Accession Numbers}

All primers used in this study were listed in Table S1. Sequence data were downloaded from the MSU Rice Genome Annotation Project database (http:/ / rice.plantbiology.msu.edu, accessed on 30 October 2021) [55]. The accession numbers are OsBIC1 (LOC_Os04g33610), OsBIC2 (LOC_Os02g32990), OsCRY1a (LOC_Os02g36380), OsCRY1b (LOC_Os04g37920), OsCRY2 (LOC_Os02g41550), OsGA20ox2 (LOC_Os01g66100), OsKO2 (LOC_Os06g37364), OsGA3ox2 (LOC_Os01g08220), OsGA2ox6 (LOC_Os04g44150), OsGA2ox7 (LOC_Os01g11150), OsbZIP18 (LOC_Os02g10860), OsbZIP48 (LOC_Os06g39960), GPA1 (LOC_Os05g26890), OsKAO (LOC_Os06g02019), and ubq (LOC_Os03g13170). The RNA-seq data were deposited in the National Genomics Data Center with GSA accession number CRA005544 (https:/ /ngdc.cncb.ac.cn/?lang=en, accessed on 30 October 2021).

\subsection{Plasmid Construction, Plant Materials and Growth Conditions}

To generate OsBIC1 and OsBIC2 overexpression lines, the Coding DNA sequence (CDS) of OsBIC1 (651 bp) and OsBIC2 (585 bp) were amplified from the cDNA of young seedlings of Nipponbare wild type and inserted into the pHCF vector at the PstI site using the Infusion ${ }^{\circledR}$ HD Cloning Kit (Clontech, 639650), respectively [56]. To obtain the CRISPR/Cas9-engineered mutants, gRNA recognition sites of different genes were designed using the CRISPR-P website (http:/ / crispr.hzau.edu.cn, accessed on 30 October 2021) and inserted into the pCas9-OsU3-sgRNA vector at the XbalI site using the Infusion ${ }^{\circledR}$ HD Cloning Kit. The above expression plasmids were individually introduced into the Agrobacterium tumefaciens strain EHA105 via electroporation and then transformed into Kita-ake (Oryza sativa L. subsp. Japonica) wild-type plants [57]. Wild-type (Kita-ake) and indicated transgenic rice were cultivated in a field in Beijing $\left(39^{\circ} 54^{\prime} \mathrm{N}, 116^{\circ} 23^{\prime} \mathrm{E}\right)$ under natural conditions from May to October (sunny day, light intensity $>500 \mu \mathrm{mol} \mathrm{m} \mathrm{m}^{-2} \mathrm{~s}^{-1}$ ). To confirm the leaf sheath length phenotypes under different light conditions, wild-type and indicated transgenic rice were grown under continuous dark, blue light, red light, or far-red light conditions in a controlled growth chamber $\left(28^{\circ} \mathrm{C}\right)$ for 14 days. The anti-OsCRY1a, antiOsCRY1b, and anti-OsCRY2 polyclonal antibodies were generated by inoculating rabbits with TF-His-OsCRY1a (524-655 aa), TF-His-OsCRY1b (528-650 aa), and TF-His-OsCRY2 (407-651 aa) recombination protein, respectively. The protein of OsCRY1a (524-655 aa), OsCRY1b (528-650 aa), and OsCRY2 (407-651 aa) were expressed by using $p$ Cold-TF vector from TaKaRa (Cat\#3365), the antibody was made in ABclonal Biotechnology Ltd. (Wuhan, China).

\subsection{Yeast Two-Hybrid Assays}

The yeast two-hybrid assay was performed according to the manufacturer's instructions (ProQues two-hybrid system with Gateway technology, Invitrogen, Waltham, MA, USA). The coding DNA sequences (CDSs) of OsBIC1 and OsBIC2 were individually inserted into the bait vector pBridge that had been digested with EcoRI and BamHI using the Infusion ${ }^{\circledR}$ HD Cloning Kit. The CDSs of OsCRY1a, OsCRY1b, and OsCRY2 were individually fused in the prey vector pGADT7 at the EcoRI and BamHI sites using the Infusion ${ }^{\circledR}$ HD Cloning Kit. The bait and prey plasmids were co-transformed into the yeast strain AH109 to test their interactions. Cultures containing the fusion protein were plated onto SD/-Tryptophan/-Leucine (SD/-L-W) and SD/-Leucine/-Tryptophan/-Histidine/Adenine (SD/-L-W-H-Ade) plates and allowed to grow for $48 \mathrm{~h}$ before being photographed. The empty vector (BD) was used as a negative control.

\subsection{Firefly Luciferase Complementation Imaging Assays in N. benthamiana}

The CDS of OsBIC1 and OsBIC2 were individually inserted into the pCambia1300LUC $^{\mathrm{N}}$ vector at the KpnI and SalI sites. The CDS of OsCRY1a, OsCRY1b and OsCRY2 were individually cloned into the pCambia1300-LUC ${ }^{\mathrm{C}}$ vector at the BglII and MluI sites. The LUC $^{\mathrm{N}}$ and LUC ${ }^{\mathrm{C}}$ plasmids were individually introduced into Agrobacterium tumefaciens strain EHA105 via electroporation and then infiltrated into $N$. benthamiana leaves with vari- 
ous combinations. The assays were performed according to the previous description [58]. A low-light cooled charge-coupled device camera (Tanon 5200, Beijing, China) was used to capture the LUC image. The exposure time of LUC was $10 \mathrm{~min}$ for the images.

\subsection{Longitudinal Sections Histological Analysis}

WT and each indicated mutant were grown under continuous blue light conditions at $28{ }^{\circ} \mathrm{C}$ for 14 days $\left(35 \mu \mathrm{mol} \mathrm{m}{ }^{-2} \mathrm{~s}^{-1}\right)$. The second leaf sheath was fixed in FAA solution $(60 \%$ $(v / v)$ ethanol, dehydrated through a series of graded ethanol concentrations, and, finally, embedded in paraffin. Tissue sections were cut with a Leica rotary microtome, stained with Hematoxylin solution, and then imaged under a light microscope.

\subsection{Sample Collection and qRT-PCR Analysis}

Seeds of wild-type (WT) and indicated transgenic rice were germinated for 2 days on wet filter paper in Petri-dishes at $37^{\circ} \mathrm{C}$. The uniformly germinated seeds were picked up and sown into bottomless 96-well plates and hydroponically grown (distiller water with 1/10 MS). To complete the transcription analysis of GA-responsive genes, etiolated seedlings were grown under continuous dark conditions for seven-day and then exposed to blue light $\left(25 \mu \mathrm{mol} \mathrm{m}{ }^{-2} \mathrm{~s}^{-1}\right)$ or kept in the dark for $2 \mathrm{~h}$ to be collected. Samples were named as blue light treatment plants and dark treatment plants, respectively. Three independent biological replicates were analyzed, and three replicate reactions were used for each sample. All the above samples were used to extract total RNA using TRIzol reagent (Invitrogen). The first complementary DNA and cDNA were synthesized from DNase-treated total RNA (3 $\mu$ g, reaction total volume $20 \mu \mathrm{L}$ ) using a TransScript ${ }^{\circledR}$ II One-Step gDNA Removal and cDNA Synthesis SuperMix kit (TransGen Biotech, AT311, Beijing, China). qRT-PCR was performed in 96-well optical plates using an SYBR Green RT-PCR kit (Takara, RR420A) and a Roche Light Cycler 480. Ubiquitin ( $\mathrm{Ubq}$ ) was not the blue light-regulated gene (fold change $<2$ or $p$ value $>0.01)$. Therefore, the value of gene expression was normalized to Ubq (Table S3).

\subsection{RNA-seq and Data Analysis}

To complete the high-throughput RNA-sequencing assay, etiolated seedlings were grown under continuous dark conditions for seven days and then exposed to blue light $\left(25 \mu \mathrm{mol} \mathrm{m}{ }^{-2} \mathrm{~s}^{-1}\right)$ or kept in the dark for $2 \mathrm{~h}$ to be collected for RNA extraction. The sequencing library was constructed following the manufacturer's instructions (Illumina Inc., San Diego, CA, USA). Paired-end sequencing libraries with an insert size of approximately $200 \mathrm{bp}$ were sequenced on an Illumina HiSeq 2000 sequencer at the BIOMARKER Company in Beijing. RNA-seq clean reads of three biological replicates were mapped to the O. sativa ssp. japonica reference genome after removing adaptor and low-quality nucleotides byTopHat [59]. The expression value was calculated in FPKM (fragments per kilobase of exon model per million mapped fragments), and differentially expressed genes were defined as those that showed a factor of $>2$ change of mRNA (fold change $(\mathrm{FC})>2, p$ value $<0.01$, False discovery rate $(\mathrm{FDR})<0.01)$. Three independent biological replicates were analyzed, and three replicate reactions were used for each sample. To validate the utility and accuracy of RNA-seq, 18 out of 1793 blue light-regulated genes were chosen to test through qRT-PCR, which accounted for a $1 \%$ fraction of the total differentially expressed genes. The FPKM values of 18 validations genes ranged from 1 to 200 (low expression to high expression), and the fold change ranged from -250 to 250 (down-regulated and up-regulated) in WT-Dark RNA-seq data (Figures S5 and S6). Four out of the eighteen validations genes were related to blue light response (OsBIC1, OsBIC2, OsSPA1, and OsCOP1). Seven out of the eighteen validations genes were related to GA-responsive (OsGA20ox2, OsKO2, OsGA3ox2, OsGA2ox6, OsGA2ox7, OsbZIP18, and OsbZIP48). Seven of the eighteen validations genes remained unknown (LOC_Os01g47370, LOC_Os02g04510, LOC_Os03g12700, LOC_Os06g07914,LOC_Os03g61160, LOC_Os02g37330, and LOC_Os04g55210). The fold change trend of 18 genes in qRT-PCR was consistent with that in RNA-seq data 
(Figures S5 and S6). Moreover, Correlation analysis of fold change further confirmed that the relationship was linear between RNA-seq and qRT-PCR data, of which the correlation value (R2) was 0.8316 (Figure S7).

\subsection{GA Content Analysis Assays}

The GA content assay was performed following the manufacturer's instructions of plant GA determination detection ELISA Kit. WT and each indicated mutants were grown under continuous blue light conditions at $28^{\circ} \mathrm{C}$ for 14 days $\left(35 \mu \mathrm{mol} \mathrm{m}^{-2} \mathrm{~s}^{-1}\right)$. One gram of fresh leaves was harvested and ground into powder in liquid nitrogen. Then, tissues were resuspended in $9 \mathrm{~mL}$ PBS buffer ( $\mathrm{pH}$ 7.2-7.4). A sample resuspension of $10 \mu \mathrm{L}$ and $40 \mu \mathrm{L}$ sample dilution were added to wells together, incubated for $30 \mathrm{~min}$ at $37^{\circ} \mathrm{C}$, repeatedly rinsed with wash solution. A total of $50 \mu \mathrm{L}$ HRP-Conjugate reagent was added to each well, incubated for $30 \mathrm{~min}$ at $37^{\circ} \mathrm{C}$, repeatedly rinsed with wash solution. Then, $50 \mu \mathrm{L}$ chromogen solution $\mathrm{A}$ and chromogen solution $\mathrm{B}$ were added to each well, evading the light preservation for $10 \mathrm{~min}$ at $37^{\circ} \mathrm{C}$. Finally, $50 \mu \mathrm{L}$ stop solution was added to each well to stop the reaction (the blue color changes to yellow color). An enzyme standard instrument under $450 \mathrm{~nm}$ wavelength determined absorbance (OD value) and calculated the sample concentration.

\section{Conclusions}

Our work identified the genetic contribution of OsBICs to both leaf sheath elongation and plant height growth. Our results demonstrated that OsBIC1 and OsCRYs worked together to regulate epidermal cell elongation and control blue light-induced leaf sheath elongation through the GA-responsive pathway.

Supplementary Materials: The following are available online at https://www.mdpi.com/article/10 .3390/ijms23010287/s1.

Author Contributions: J.L. and H.L. conceived of and designed experiments and edited the manuscript; C.L., X.W. and L.Z. performed the experiment; C.Z., C.Y., B.L. and T.Z. helped in performing the experiment and writing this manuscript. All authors have read and agreed to the published version of the manuscript.

Funding: This research was supported by grants from the National Natural Science Foundation of China (No. 31771758) to J.L. and the National Transgenic Major Project of China (No. 2018ZX0800925B) to J.L.

Institutional Review Board Statement: Not applicable.

Informed Consent Statement: Not applicable.

Data Availability Statement: The data presented in this study are available on request from the corresponding author.

Conflicts of Interest: The authors declare no conflict of interest.

\section{References}

1. Lin, C.; Shalitin, D. Cryptochrome structure and signal transduction. Annu. Rev. Plant Biol. 2003, 54, 469-496. [CrossRef] [PubMed]

2. Ahmad, M.; Cashmore, A.R. HY4 gene of A. thaliana encodes a protein with characteristics of a blue-light photoreceptor. Nature 1993, 366, 162-166. [CrossRef] [PubMed]

3. Hoffman, P.D.; Batschauer, A.; Hays, J.B. PHH1, a novel gene from Arabidopsis thaliana that encodes a protein similar to plant blue-light photoreceptors and microbial photolyases. Mol. Gen. Genet. 1996, 253, 259-265. [CrossRef] [PubMed]

4. Lin, C.; Yang, H.; Guo, H.; Mockler, T.; Chen, J.; Cashmore, A.R. Enhancement of blue-light sensitivity of Arabidopsis seedlings by a blue light receptor cryptochrome 2. Proc. Natl. Acad. Sci. USA 1998, 95, 2686-2690. [CrossRef]

5. Wang, Q.; Zuo, Z.; Wang, X.; Gu, L.; Yoshizumi, T.; Yang, Z.; Yang, L.; Liu, Q.; Liu, W.; Han, Y.J.; et al. Photoactivation and inactivation of Arabidopsis cryptochrome 2. Science 2016, 354, 343-347. [CrossRef]

6. Wang, X.; Wang, Q.; Han, Y.J.; Liu, Q.; Gu, L.; Yang, Z.; Su, J.; Liu, B.; Zuo, Z.; He, W.; et al. A CRY-BIC negative-feedback circuitry regulating blue light sensitivity of Arabidopsis. Plant J. 2017, 92, 426-436. [CrossRef] 
7. Wang, Q.; Zuo, Z.; Wang, X.; Liu, Q.; Gu, L.; Oka, Y.; Lin, C. Beyond the photocycle-how cryptochromes regulate photoresponses in plants? Curr. Opin. Plant Biol. 2018, 45, 120-126. [CrossRef]

8. Xu, P.; Xiang, Y.; Zhu, H.; Xu, H.; Zhang, Z.; Zhang, C.; Zhang, L.; Ma, Z. Wheat cryptochromes: Subcellular localization and involvement in photomorphogenesis and osmotic stress responses. Plant Physiol. 2008, 149, 760-774. [CrossRef]

9. Xu, P.; Zhu, H.; Xu, H.; Zhang, Z.; Zhang, C.; Zhang, L.; Ma, Z. Composition and phylogenetic analysis of wheat cryptochrome gene family. Mol. Biol. Rep. 2009, 37, 825-832. [CrossRef]

10. Ishibashi, N.; Setoguchi, H. Polymorphism of DNA sequences of cryptochrome genes is not associated with the photoperiodic flowering of wild soybean along a latitudinal cline. J. Plant Res. 2012, 125, 483-488. [CrossRef]

11. Meng, Y.; Li, H.; Wang, Q.; Liu, B.; Lin, C. Blue light-dependent interaction between cryptochrome2 and CIB1 regulates transcription and leaf senescence in soybean. Plant Cell 2013, 25, 4405-4420. [CrossRef] [PubMed]

12. Barrero, J.M.; Downie, B.A.; Xu, Q.; Gubler, F. A Role for Barley CRYPTOCHROME1 in light regulation of grain dormancy and germination. Plant Cell 2014, 26, 1094-1104. [CrossRef]

13. Matsumoto, N.; Hirano, T.; Iwasaki, T.; Yamamoto, N. Functional analysis and intracellular localization of rice cryptochromes. Plant Physiol. 2003, 133, 1494-1503. [CrossRef] [PubMed]

14. Hirose, F.; Shinomura, T.; Tanabata, T.; Shimada, H.; Takano, M. Involvement of rice cryptochromes in de-etiolation responses and flowering. Plant Cell Physiol. 2006, 47, 915-925. [CrossRef] [PubMed]

15. Zhang, Y.C.; Gong, S.F.; Li, Q.H.; Sang, Y.; Yang, H.Q. Functional and signaling mechanism analysis of rice CRYPTOCHROME 1. Plant J. 2006, 46, 971-983. [CrossRef]

16. Yamaguchi, S. Gibberellin metabolism and its regulation. Annu. Rev. Plant Biol. 2008, 59, 225-251. [CrossRef] [PubMed]

17. Wang, W.X.; Lian, H.L.; Zhang, L.D.; Mao, Z.L.; Li, X.M.; Xu, F.; Li, L.; Yang, H.Q. Transcriptome analyses reveal the involvement of both $\mathrm{C}$ and $\mathrm{N}$ termini of cryptochrome 1 in its regulation of phytohormone-responsive gene expression in Arabidopsis. Front. Plant Sci. 2016, 7, 294. [CrossRef] [PubMed]

18. Szekeres, M.; Nemeth, K.; Koncz-Kalman, Z.; Mathur, J.; Kauschmann, A.; Altmann, T.; Redei, G.P.; Nagy, F.; Schell, J.; Koncz, C. Brassinosteroids rescue the deficiency of CYP90, a cytochrome P450, controlling cell elongation and de-etiolation in Arabidopsis. Cell 1996, 85, 171-182. [CrossRef]

19. Richards, D.E.; King, K.E.; Ait-Ali, T.; Harberd, N.P. How gibberellin regulates plant growth and development: A molecular genetic analysis of gibberellin signaling. Annu. Rev. Plant Physiol. Plant Mol. Biol. 2001, 52, 67-88. [CrossRef]

20. Ueguchi-Tanaka, M.; Ashikari, M.; Nakajima, M.; Itoh, H.; Katoh, E.; Kobayashi, M.; Chow, T.Y.; Hsing, Y.I.; Kitano, H.; Yamaguchi, I.; et al. Gibberellin insensitive DWARF1 encodes a soluble receptor for gibberellin. Nature 2005, 437, 693-698. [CrossRef]

21. Thomas, S.G.; Rieu, I.; Steber, C.M. Gibberellin metabolism and signaling. Vitam. Horm. 2005, 72, 289-338. [CrossRef] [PubMed]

22. Zhao, X.; Yu, X.; Foo, E.; Symons, G.M.; Lopez, J.; Bendehakkalu, K.T.; Xiang, J.; Weller, J.L.; Liu, X.; Reid, J.B.; et al. A study of gibberellin homeostasis and cryptochrome-mediated blue light inhibition of hypocotyl elongation. Plant Physiol. 2007, 145, 106-118. [CrossRef]

23. He, S.B.; Wang, W.X.; Zhang, J.Y.; Xu, F.; Lian, H.L.; Li, L.; Yang, H.Q. The CNT1 domain of Arabidopsis CRY1 alone is sufficient to mediate blue light inhibition of hypocotyl elongation. Mol. Plant 2015, 8, 822-825. [CrossRef] [PubMed]

24. Hirose, F.; Inagaki, N.; Hanada, A.; Yamaguchi, S.; Kamiya, Y.; Miyao, A.; Hirochika, H.; Takano, M. Cryptochrome and phytochrome cooperatively but independently reduce active gibberellin content in rice seedlings under light irradiation. Plant Cell Physiol. 2012, 53, 1570-1582. [CrossRef] [PubMed]

25. Zhang, Q.; Li, H.; Li, R.; Hu, R.; Fan, C.; Chen, F.; Wang, Z.; Liu, X.; Fu, Y.; Lin, C. Association of the circadian rhythmic expression of GmCRY1a with a latitudinal cline in photoperiodic flowering of soybean. Proc. Natl. Acad. Sci. USA 2008, 105, 21028-21033. [CrossRef]

26. Lyu, X.; Cheng, Q.; Qin, C.; Li, Y.; Xu, X.; Ji, R.; Mu, R.; Li, H.; Zhao, T.; Liu, J.; et al. GmCRY1s modulate gibberellin metabolism to regulate soybean shade avoidance in response to reduced blue light. Mol. Plant 2021, 14, 298-314. [CrossRef]

27. Itoh, H.; Tatsumi, T.; Sakamoto, T.; Otomo, K.; Toyomasu, T.; Kitano, H.; Ashikari, M.; Ichihara, S.; Matsuoka, M. A rice semi-dwarf gene, Tan-Ginbozu (D35), encodes the gibberellin biosynthesis enzyme, ent-kaurene oxidase. Plant Mol. Biol. 2004, 54, 533-547. [CrossRef]

28. Sasaki, A.; Ashikari, M.; Ueguchi-Tanaka, M.; Itoh, H.; Nishimura, A.; Swapan, D.; Ishiyama, K.; Saito, T.; Kobayashi, M.; Khush, G.S.; et al. Green revolution: A mutant gibberellin-synthesis gene in rice. Nature 2002, 416, 701-702. [CrossRef]

29. Asano, K.; Yamasaki, M.; Takuno, S.; Miura, K.; Katagiri, S.; Ito, T.; Doi, K.; Wu, J.; Ebana, K.; Matsumoto, T.; et al. Artificial selection for a green revolution gene during japonica rice domestication. Proc. Natl. Acad. Sci. USA 2011, 108, 11034-11039. [CrossRef]

30. Sakamoto, T.; Miura, K.; Itoh, H.; Tatsumi, T.; Ueguchi-Tanaka, M.; Ishiyama, K.; Kobayashi, M.; Agrawal, G.K.; Takeda, S.; Abe, K.; et al. An overview of gibberellin metabolism enzyme genes and their related mutants in rice. Plant Physiol. 2004, 134, 1642-1653. [CrossRef]

31. Hsieh, K.T.; Liu, S.H.; Wang, I.W.; Chen, L.J. Phalaenopsis orchid miniaturization by overexpression of OsGA2ox6, a rice GA2-oxidase gene. Bot. Stud. 2020, 61, 10. [CrossRef] [PubMed]

32. Huang, J.; Tang, D.; Shen, Y.; Qin, B.; Hong, L.; You, A.; Li, M.; Wang, X.; Yu, H.; Gu, M.; et al. Activation of gibberellin 2-oxidase 6 decreases active gibberellin levels and creates a dominant semi-dwarf phenotype in rice (Oryza sativa L.). J. Genet. Genom. 2010, 37, 23-36. [CrossRef] 
33. Ueguchi-Tanaka, M.; Nakajima, M.; Katoh, E.; Ohmiya, H.; Asano, K.; Saji, S.; Hongyu, X.; Ashikari, M.; Kitano, H.; Yamaguchi, I.; et al. Molecular interactions of a soluble gibberellin receptor, GID1, with a rice DELLA protein, SLR1, and gibberellin. Plant Cell 2007, 19, 2140-2155. [CrossRef] [PubMed]

34. Ueguchi-Tanaka, M.; Nakajima, M.; Motoyuki, A.; Matsuoka, M. Gibberellin receptor and its role in gibberellin signaling in plants. Annu. Rev. Plant Biol. 2007, 58, 183-198. [CrossRef]

35. Burman, N.; Bhatnagar, A.; Khurana, J.P. OsbZIP48, a HY5 Transcription factor ortholog, exerts pleiotropic effects in lightregulated development. Plant Physiol. 2018, 176, 1262-1285. [CrossRef] [PubMed]

36. Mockler, T.C.; Guo, H.; Yang, H.; Duong, H.; Lin, C. Antagonistic actions of Arabidopsis cryptochromes and phytochrome B in the regulation of floral induction. Development 1999, 126, 2073-2082. [CrossRef] [PubMed]

37. Zhou, L.; Liu, S.; Wu, W.; Chen, D.; Zhan, X.; Zhu, A.; Zhang, Y.; Cheng, S.; Cao, L.; Lou, X.; et al. Dissection of genetic architecture of rice plant height and heading date by multiple-strategy-based association studies. Sci. Rep. 2016, 6, 29718. [CrossRef] [PubMed]

38. Colebrook, E.H.; Thomas, S.G.; Phillips, A.L.; Hedden, P. The role of gibberellin signalling in plant responses to abiotic stress. J. Exp. Biol. 2014, 217, 67-75. [CrossRef] [PubMed]

39. Kwon, C.T.; Paek, N.C. Gibberellic Acid: A key phytohormone for spikelet fertility in rice grain production. Int. J. Mol. Sci. 2016, 17, 794. [CrossRef]

40. Kaneko, M.; Itoh, H.; Inukai, Y.; Sakamoto, T.; Ueguchi-Tanaka, M.; Ashikari, M.; Matsuoka, M. Where do gibberellin biosynthesis and gibberellin signaling occur in rice plants? Plant J. 2003, 35, 104-115. [CrossRef]

41. Wu, Y.; Wang, Y.; Mi, X.F.; Shan, J.X.; Li, X.M.; Xu, J.L.; Lin, H.X. The QTL GNP1 Encodes GA20ox1, Which Increases Grain number and yield by increasing cytokinin activity in rice panicle meristems. PLoS Genet. 2016, 12, e1006386. [CrossRef] [PubMed]

42. Deveshwar, P.; Prusty, A.; Sharma, S.; Tyagi, A.K. Phytohormone-mediated molecular mechanisms involving multiple genes and QTL govern grain number in rice. Front Genet. 2020, 11, 586462. [CrossRef] [PubMed]

43. Weller, J.L.; Hecht, V.; Vander Schoor, J.K.; Davidson, S.E.; Ross, J.J. Light regulation of gibberellin biosynthesis in pea is mediated through the COP1/HY5 pathway. Plant Cell 2009, 21, 800-813. [CrossRef] [PubMed]

44. Lee, J.; He, K.; Stolc, V.; Lee, H.; Figueroa, P.; Gao, Y.; Tongprasit, W.; Zhao, H.; Lee, I.; Deng, X.W. Analysis of transcription factor HY5 genomic binding sites revealed its hierarchical role in light regulation of development. Plant Cell 2007, 19, 731-749. [CrossRef]

45. Hirano, K.; Kouketu, E.; Katoh, H.; Aya, K.; Ueguchi-Tanaka, M.; Matsuoka, M. The suppressive function of the rice DELLA protein SLR1 is dependent on its transcriptional activation activity. Plant J. 2012, 71, 443-453. [CrossRef]

46. Ikeda, A.; Ueguchi-Tanaka, M.; Sonoda, Y.; Kitano, H.; Koshioka, M.; Futsuhara, Y.; Matsuoka, M.; Yamaguchi, J. Slender rice, a constitutive gibberellin response mutant, is caused by a null mutation of the SLR1 gene, an ortholog of the height-regulating gene GAI/RGA/RHT/D8. Plant Cell 2001, 13, 999-1010. [CrossRef]

47. Blanco-Tourinan, N.; Legris, M.; Minguet, E.G.; Costigliolo-Rojas, C.; Nohales, M.A.; Iniesto, E.; Garciotaa-Leomicronn, M.; Paciotan, M.; Heucken, N.; Blomeier, T.; et al. COP1 destabilizes DELLA proteins in Arabidopsis. Proc. Natl. Acad. Sci. USA 2020, 117, 13792-13799. [CrossRef]

48. Liu, B.; Zuo, Z.; Liu, H.; Liu, X.; Lin, C. Arabidopsis cryptochrome 1 interacts with SPA1 to suppress COP1 activity in response to blue light. Genes Dev. 2011, 25, 1029-1034. [CrossRef]

49. Lian, H.L.; He, S.B.; Zhang, Y.C.; Zhu, D.M.; Zhang, J.Y.; Jia, K.P.; Sun, S.X.; Li, L.; Yang, H.Q. Blue-light-dependent interaction of cryptochrome 1 with SPA1 defines a dynamic signaling mechanism. Genes Dev. 2011, 25, 1023-1028. [CrossRef]

50. Saijo, Y.; Sullivan, J.A.; Wang, H.; Yang, J.; Shen, Y.; Rubio, V.; Ma, L.; Hoecker, U.; Deng, X.W. The COP1-SPA1 interaction defines a critical step in phytochrome A-mediated regulation of HY5 activity. Genes Dev. 2003, 17, 2642-2647. [CrossRef]

51. Zhu, D.; Maier, A.; Lee, J.H.; Laubinger, S.; Saijo, Y.; Wang, H.; Qu, L.J.; Hoecker, U.; Deng, X.W. Biochemical characterization of Arabidopsis complexes containing constitutively PHOTOMORPHOGENIC1 and suppressor of PHYA proteins in light control of plant development. Plant Cell 2008, 20, 2307-2323. [CrossRef] [PubMed]

52. Zuo, Z.; Liu, H.; Liu, B.; Liu, X.; Lin, C. Blue light-dependent interaction of CRY2 with SPA1 regulates COP1 activity and floral initiation in Arabidopsis. Curr. Biol. 2011, 21, 841-847. [CrossRef] [PubMed]

53. McNellis, T.W.; von Arnim, A.G.; Deng, X.W. Overexpression of Arabidopsis COP1 results in partial suppression of light-mediated development: Evidence for a light-inactivable repressor of photomorphogenesis. Plant Cell 1994, 6, 1391-1400. [CrossRef] [PubMed]

54. Seo, H.S.; Yang, J.Y.; Ishikawa, M.; Bolle, C.; Ballesteros, M.L.; Chua, N.H. LAF1 ubiquitination by COP1 controls photomorphogenesis and is stimulated by SPA1. Nature 2003, 423, 995-999. [CrossRef]

55. Kawahara, Y.; de la Bastide, M.; Hamilton, J.P.; Kanamori, H.; McCombie, W.R.; Ouyang, S.; Schwartz, D.C.; Tanaka, T.; Wu, J.; Zhou, S.; et al. Improvement of the Oryza sativa Nipponbare reference genome using next generation sequence and optical map data. Rice 2013, 6, 4. [CrossRef]

56. Cornejo, M.J.; Luth, D.; Blankenship, K.M.; Anderson, O.D.; Blechl, A.E. Activity of a maize ubiquitin promoter in transgenic rice. Plant Mol. Biol. 1993, 23, 567-581. [CrossRef] [PubMed]

57. Hiei, Y.; Ohta, S.; Komari, T.; Kumashiro, T. Efficient transformation of rice (Oryza sativa L.) mediated by Agrobacterium and sequence analysis of the boundaries of the T-DNA. Plant J. 1994, 6, 271-282. [CrossRef] 
58. Hua, D.; Wang, C.; He, J.; Liao, H.; Duan, Y.; Zhu, Z.; Guo, Y.; Chen, Z.; Gong, Z. A plasma membrane receptor kinase, GHR1, mediates abscisic acid- and hydrogen peroxide-regulated stomatal movement in Arabidopsis. Plant Cell 2012, 24, $2546-2561$. [CrossRef] [PubMed]

59. Trapnell, C.; Pachter, L.; Salzberg, S.L. TopHat: Discovering splice junctions with RNA-Seq. Bioinformatics 2009, $25,1105-1111$. [CrossRef] 